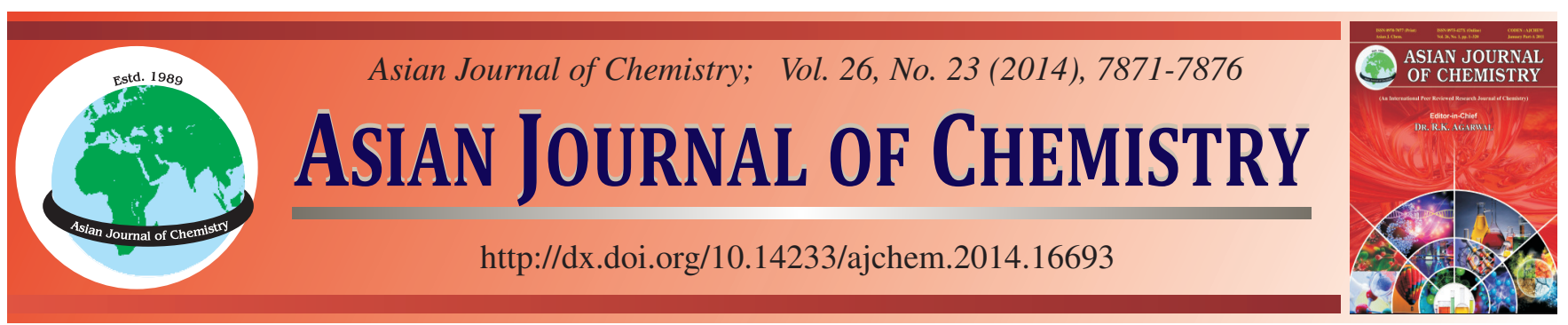

REVIEW

\title{
Transport Phenomena and Evaporation on Interface of Gas-Liquid by Reversed-Flow Gas Chromatography
}

\section{H.H. Mohammad ${ }^{1, *}$, Khalisanni Khalid ${ }^{2}$ and Sharifuddin Mohd. Zain ${ }^{1}$}

${ }^{1}$ Chemistry Department, University of Malaya, 50603 Kuala Lumpur, Malaysia

${ }^{2}$ Food and Agricultural Analysis Laboratory Program, Technical Service Centre, Malaysian Agricultural Research and Development Institute (MARDI), 43400 Serdang, Selangor, Malaysia

*Corresponding author: E-mail: enal_fifi@yahoo.com; typhloids@hotmail.com

Received: 14 November 2013; $\quad$ Accepted: 4 April 2014; $\quad$ Published online: 15 November 2014;

AJC-16254

Gas-liquid interface plays a major interest in environmental studies especially when the researchers are interested to study the diffusion coefficients and rate coefficients of the liquid under studies into the chosen carrier gas. The study of the gas-liquid interface by reversedflow gas chromatography (RF-GC) is based on Ficks first law in one dimensional and Henry's law. Based on the two laws, an extensive works have been done previously by using reversed-flow gas chromatography methodologies to determine physiochemical properties on the gas-liquid interface. The setup for this method is just by modifying the commercial gas chromatography by including diffusion column which orientated right angle to the sampling which carried the carrier gas. The bottom part consists of the glass bottle which holds the liquid under studies. The usage of six-port or four-port valves play a major role in this methodologies since the equipment allows the carrier gas to reverse and retain its original flow from time to time and thus creating a 'sample peak' which sits on the continuous signal versus time chromatogram. The diffusion column which contains stagnant carrier gas accounts for the stationary phase and thus contributes to the physiochemicals phenomena of the interface. This methodology can be considered as fast sampling procedure as compared to the others in term of determining rate coefficients and diffusion coefficients of liquid sample into the carrier gas. The methods not only important in environmental investigation but can also be applied in the area of material science, food chemistry, nanotechnology, biological science and chemical technology.

Keywords: Diffusion coefficients, Fuller-shettlar-giddings equation, Gas-liquid interphase, Reversed-flow gas chromatography.

ᄂ - - - - - - - - - - - - - - - - - - - - - - - - -

\section{INTRODUCTION}

Reversed-flow gas chromatography (RF-GC) is different from conventional gas chromatography essentially because it consists of sampling cell, which is composed of sampling and diffusion columns. The carrier gas flows continuously through sampling column while it remains stagnant in the diffusion column. A part or whole of diffusion column can be filled with solid or liquid substance under study ${ }^{1,3-12}$. The authors will limit this review up to the application of RF-GC towards the interface of gas-liquid since the review on the other interface has been extensively describe by the previous review ${ }^{1}$. The transport phenomena across the gas-liquid for RF-GC methodologies much concern on the diffusion of respective solute into the carrier gas. Thus, the first part of this manuscript will try to explore the works done by previous researcher on determination of the diffusion coefficients on the liquid-gas interface. Next, the author explain in the great details on the experimental set up for the determination of the diffusion rates and coeffi- cient rates of liquid under studies with the application of surfactant monolayer at the liquid-gas interface which part of the author's current work ${ }^{46}$. Finally, the author will discuss the modification done on the lower part of the diffusion column of the RF-GC to calculate other physico-chemical measurements within the gas-liquid interface.

Diffusion of gases in liquids: Most of the methods used in the early measurement of diffusion coefficients of the liquid systems were based on static bulk equilibration methods (e.g., gravimetric sorption/desorption $)^{1}$. The limitation of this method is that it relies on the sorption and bulk equilibration which cannot be applied to solute-solvent system if the solute presents in a minute amounts. As a consequence, the time for sorption may be large because the diffusion coefficient may be small. But, the accuracy of this method may be declined due the small amount of the solute presents.

Evaporation of liquids: Evaporation is a process which converting a substance which in the liquid phase into the vapor phase. The process must overcome the strong forces of 
attraction between the molecules, which are balanced equally strong forces of repulsion. Thus, in order to overcome the potential energy of attraction, the molecules require kinetic energy which is a function of temperature. The molecules obeys the following equation if the process occurs at the constant volume ${ }^{2}$,

$$
\frac{\mathrm{n}_{\mathrm{v}}}{\mathrm{n}_{1}}=\mathrm{e}^{\frac{\Delta \mathrm{E}}{\mathrm{RT}}}
$$

where $\mathrm{n}_{v}$ is the number of molecules per milliliter in the vapor, $\mathrm{n}_{1}$ is the number of molecules per milliliter in the liquid, $\Delta \mathrm{E}$ is the difference in molar internal energy of the gas and liquid, $\mathrm{R}$ is the gas constant and $\mathrm{T}$ is the absolute temperature.

When the molecules gain the kinetic energy, they will evaporate from the liquid which results the average kinetic energy of the remaining molecules decreases. This can be observed as the temperature drops at the beginning of the process. Thus, heat must be released to the liquid in order to maintain the temperature. Realistically, the evaporation process occurs at constant pressure which differs from the prediction that it occurs at the constant volume. Thus, ones can relate the evaporation process with the first law of thermodynamic by the relation ${ }^{2}$ :

$$
\Delta \mathrm{H}=\Delta \mathrm{E}+\mathrm{P} \Delta \mathrm{V}
$$

where $\mathrm{P} \Delta \mathrm{V}$, portrays the work done by vapor at constant atmospheric pressure which result in volume expansion. Thus, $\Delta \mathrm{H}$ can be describe as the energy required to evaporate one mole of liquid at constant pressure, or simply called the molar heat of vaporization.

Since the gas obeys the ideal gas law to the first approximation $(\mathrm{PV}=\mathrm{RT})^{2}$, thus the relation gives the latent heat of vaporization:

$$
\Delta \mathrm{H}=\Delta \mathrm{E}-\mathrm{RT}
$$

$\Delta \mathrm{H}$ is a function of temperature is usually measured by calorimeter at the normal boiling point.

The factors that affecting the rate of evaporation of a liquid are as follow: (i) Concentration of the substance evaporating in the air, (ii) Concentration of the other substances in the air, (iii) Concentration of the other substances in the liquid (impurities), (iv) Flow rate of air just above the liquid surface, (v) Inter-molecular forces (attractive-repulsive) between the molecule of the liquid, (vi) Pressure at the surface of the liquid, (vii) Surface area of the liquid that is being exposed, (viii) Temperature of the liquid, (ix) Density of the liquid, (x) Monolayer thickness that being applied at the gas liquid interface, (xi) Intermolecular interference on the surface of liquid bodies.

General principle of reversed-flow gas chromatography: The technique of reversed-flow gas chromatography was first introduced by Prof. N.A. Katsanos and his co-workers at the Laboratory of Physical Chemistry, University of Patras, Athens, Greece $^{3-16}$. In the recent review of the reversed-flow gas chromatography ${ }^{17}$, the author did mention that RF-GC is first proposed for kinetic studies heterogenous catalysis ${ }^{18}$ and then the method is applied to the dehydration of alcohols and the deamination of primary amines ${ }^{17-19}$. Many publications using this technique have been published, this may include the determination of gas diffusion coefficients in binary and ternary gas mixture ${ }^{5-8}$, determination of adsorption equilibrium constant $^{9}$, determination of rate constants, activation parameters as well as determination of catalytic conversion of reactants into products for various important surface catalyzed reactions ${ }^{13-15,20}$ and determination of Flory-Huggins interaction parameters and solubility parameters in polymer-solvent system $^{16}$. Besides that, RF-GC also plays an important role in determination of rate coefficients for evaporation of liquids ${ }^{21}$, determination of mass transfer and partition coefficients across gas-liquid and gas-solid interfaces ${ }^{22-25}$ and in determination of adsoption energies, local monolayer capacities and local adsorption isotherms ${ }^{26,27}$. Furthermore RF-GC also has being used in determination of rate constant for sorption of various gases on bimetallic catalyst ${ }^{28,29}$ and in determination of activity coefficient $^{20}$. As far as the author concerns, RF-GC has been used to study the evaporation of the pollutant liquids under the influences of the surfactant ${ }^{30}$ as well as the vigorous works from our laboratory which measure the diffusion rates, coefficients rates and activation energy of pure liquid pollu$\operatorname{tants}^{31-39}$ can be considered as the latest publication under this area.

Reversed-flow gas chromatography is just another sampling technique that manipulates the flow of the carrier gas by reversing the flow at regular time interval with the assistance of four or six-port valve. The process can be done manually or using automatic four or six valve with suitable computer programming. Each flow reversal will produce flow perturbation on the chromatographic elution curve by having extra peaks, or will be considered as "sampling peaks" in the rest of this article as shown in the Fig. 1.

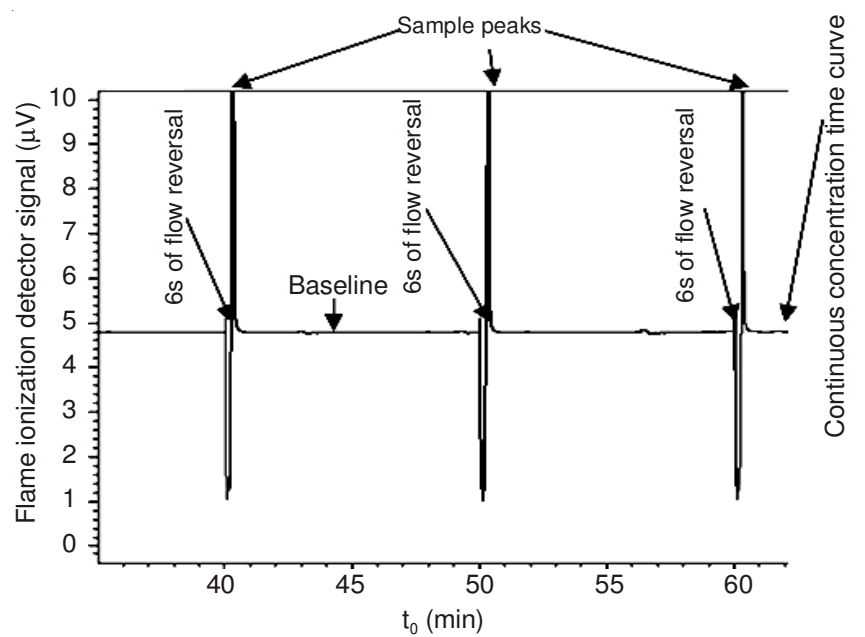

Fig. 1. Reversed flow chromatogram showing three sample peaks for the diffusion of liquid pollutant vapors into carrier gas nitrogen at $313.15 \mathrm{~K}$ and $101.325 \mathrm{kPa}$ (volumetric flow rate, $\mathrm{v}=1 \mathrm{~cm}^{3} \mathrm{~min}^{-1}$ )

\section{EXPERIMENTAL}

Experimental arrangement of the reversed-flow gas chromatography consists of the following parts:

(1) A commercial gas chromatography with any kind of detector. Flame ionization detector (FID) is highly recommended due to its sensitiveness.

(2) A sampling column which is made of unfilled stainless steel chromatographic tube of $1 / 4$ inch in diameter and having total length of 0.8-2.5 m depending on the application. 
(3) A diffusion column which is made from the same material as sampling column and oriented at right angle to the latter and usually at its middle point. The diffusion column is normally straight and relative short about $25-100 \mathrm{~cm}$. Sampling column and diffusion column can be regarded as sampling cell and this experiment, they are placed inside the oven.

(4) Sampling cell is connected to the gas inlet on one end and the detector at the other end. The connection is such way that the carrier gas flow through the sampling column (carrier gas remain stationary inside the diffusion column) can be reversed in direction at any time interval. This possible because of the existence of six port valve that connect the ends $D_{1}$ and $\mathrm{D}_{2}$ of the sampling column to the carrier gas supply and detector as shown in the Fig. 2.

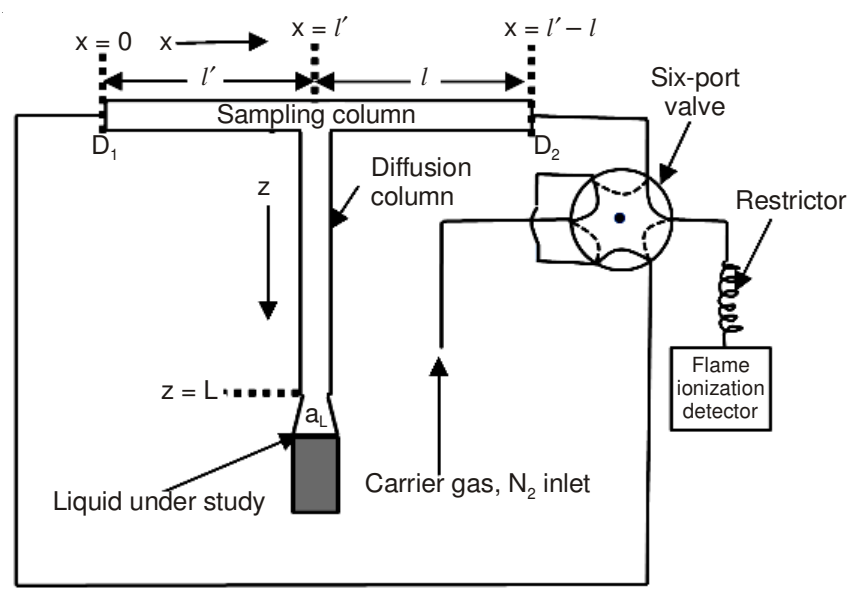

Fig. 2. Apparatus of the reversed-flow gas chromatography technique, for measuring rate coefficients and diffusion coefficients of liquids

The solid line indicates the position in which the valve is currently regulated and allowed the carrier gas to enter the column via $\mathrm{D}_{2}$ and leave at $\mathrm{D}_{1}$ toward the FID. Now, by switching the valve (indicates by the dashed line), the carrier gas direction is reversed, entering now the column via $\mathrm{D}_{1}$.

(5) A restrictor is placed before the detector to avoid the flame of FID from being extinguished when the valve is turned from one position to other.

\section{MATHEMATICAL MODEL}

The elution curves is described which follow the carrier gas reversal based on the common chromatographic sampling equation shows below ${ }^{21}$ :

$$
\begin{gathered}
\mathrm{c}=\mathrm{c}_{1}\left(l^{\prime}, \mathrm{t}_{0}+\mathrm{t}^{\prime}+\tau\right) \mathrm{u}(\tau)+\mathrm{c}_{2}\left(l^{\prime}, \mathrm{t}_{0}+\mathrm{t}^{\prime}+\tau\right)\left[1-\mathrm{u}\left(\tau-\mathrm{t}^{\prime}\right)\right] \times \\
{\left[\mathrm{u}(\tau)-\mathrm{u}\left(\tau-\mathrm{t}_{\mathrm{M}}^{\prime}\right)\right]+\mathrm{c}_{3}\left(l^{\prime}, \mathrm{t}_{0}-\mathrm{t}^{\prime}+\tau\right) \mathrm{u}\left(\mathrm{t}_{0}+\tau-\mathrm{t}^{\prime}\right)\left\{\mathrm{u}\left(\mathrm{t}-\mathrm{t}^{\prime}\right)\right.} \\
\left.\quad\left[1-\mathrm{u}\left(\tau-\mathrm{t}_{\mathrm{M}}^{\prime}\right)\right]-\mathrm{u}\left(\tau-\mathrm{t}^{\prime}\right)\left[\mathrm{u}(\tau)-\mathrm{u}\left(\tau-\mathrm{t}_{\mathrm{M}}^{\prime}\right)\right]\right\}
\end{gathered}
$$

where $\mathrm{c}$ is concentration of vapor at detector, $\mathrm{c}_{1}\left(l^{\prime}, \ldots\right), \mathrm{c}_{2}\left(l^{\prime}\right.$, $\ldots)$ and $\mathrm{c}_{3}\left(l^{\prime}, \ldots\right)$ are concentration at the point $\mathrm{x}=l^{\prime}(c f$ Fig. 1$)$ for the times shown $\left(\mathrm{t}_{0}\right.$ is the total time from placing the liquid in column to the last backward reversal of gas flow, $\mathrm{t}^{\prime}=$ time interval of backward flow, $\tau$ is the $t-t_{M}$, $t$ being the time from the last restoration of the carrier gas flow and $t_{M}$ and is the gas hold-up time of column section l: Finally the various u 's are unit step functions for the arguments shown in parentheses and $t_{M}$ is the gas hold-up time in the section $1^{\prime}$.
For $\mathrm{t}^{\prime}$ smaller than both $\mathrm{t}_{\mathrm{M}}$ and $\mathrm{t}_{\mathrm{M}}$, each sample peak produced by two successive reversals which is symmetrical and its maximum height $\mathrm{h}$ from the ending baseline is given $b^{21,47}$ :

$$
\mathrm{h} \cong 2 \mathrm{c}\left(l^{\prime}, \mathrm{t}_{0}\right)
$$

where $\mathrm{c}\left(\mathrm{l}^{\prime}, \mathrm{t}_{0}\right)$ is the vapor concentration at $\mathrm{x}=l^{\prime}$, time $\mathrm{t}_{0}$. The concentration of the liquid can be found from the diffusion equation in the column L (Fig. 1) $)^{21,47}$ :

$$
\frac{\partial \mathrm{c}_{\mathrm{z}}}{\partial \mathrm{t}_{0}}=\mathrm{D} \frac{\partial^{2} \mathrm{c}_{\mathrm{z}}}{\partial \mathrm{z}^{2}}
$$

where $\mathrm{D}$ is the diffusion coefficient of the vapor into the carrier gas. The solution of (6) is sought under the initial condition $^{21,47}$ :

$$
\mathrm{c}_{\mathrm{z}}(\mathrm{z}, 0)=0
$$

As the boundary condition at $\mathrm{z}=\mathrm{L}$ :

$$
\begin{gathered}
\mathrm{cz}\left(\mathrm{L}, \mathrm{t}_{0}\right)=\mathrm{c}\left(l, \mathrm{t}_{0}\right) \\
-\mathrm{D}\left(\frac{\partial \mathrm{c}_{\mathrm{z}}}{\partial \mathrm{z}}\right)_{\mathrm{z}=\mathrm{L}}=\operatorname{vc}\left(l^{\prime}, \mathrm{t}_{0}\right)
\end{gathered}
$$

and thus,

where $v$ is the linear velocity of carrier gas and the boundary condition at $\mathrm{z}=0$ :

$$
-\mathrm{D}\left(\frac{\partial \mathrm{c}_{\mathrm{z}}}{\partial \mathrm{z}}\right)_{\mathrm{z}=0}=\mathrm{k}_{\mathrm{c}}\left(\mathrm{c}_{0}-\mathrm{c}_{\mathrm{z}}(0)\right)
$$

where $c_{z}(0)$ is the actual concentration at the liquid interface at time $t_{0}, c_{0}$ the concentration of the vapor which would be in equilibrium with the bulk liquid phase and $\mathrm{k}_{\mathrm{c}}$ a rate coefficient for the evaporation process. Eqn. 10 expresses the equality of the diffusion flux for the removal of vapors from the liquid surface and the evaporation flux due to departure of $c_{z}$ at the surface from the equilibrium value $\mathrm{c}_{0}$.

When the Laplace transform of (6) taken with respect to $\mathrm{t}_{0}$, a linear second-order differential equation results. It can be solved by using $\mathrm{z}$ Laplace transformation yielding ${ }^{21,47}$ :

$$
\mathrm{C}_{\mathrm{z}}=\mathrm{C}_{\mathrm{z}}(0) \cos \mathrm{qz}+\frac{\mathrm{C}_{\mathrm{z}}^{\prime}(0)}{\mathrm{q}} \sin \mathrm{qz}
$$

where

$$
q=\sqrt{\left(\frac{p_{0}}{D_{0}}\right)}
$$

and $C_{z}(0)$ and $C_{z}^{\prime}(0)$ are the $t_{0}$ Laplace transform of $c_{z}(0)$ and respectively. If one combines (11) with the $t_{0}$ transforms of the boundary condition (8), (9) and (10), the Laplace transform of $\mathrm{c}\left(\mathrm{l}^{\prime}, \mathrm{t}_{0}\right)$, denoted as $\mathrm{C}\left(l^{\prime}, \mathrm{p}_{0}\right)$, is found by:

$$
\mathrm{C}\left(l^{\prime}, \mathrm{p}_{0}\right)=\frac{\mathrm{k}_{\mathrm{c}} \mathrm{c}_{0}}{\mathrm{p}_{0}} \frac{1}{\left(\mathrm{D}_{\mathrm{q}}+\frac{v \mathrm{k}_{\mathrm{c}}}{\mathrm{D}_{\mathrm{q}}}\right) \sin \mathrm{h} \mathrm{qL}+\left(\mathrm{v}+\mathrm{k}_{\mathrm{c}}\right) \cos \mathrm{h} \mathrm{qL}}
$$

The application of inverse Laplace transformation of this equation to find $\mathrm{c}\left(l^{\prime}, \mathrm{t}_{0}\right)$ is difficult. Thus, it can be achieved by using certain approximation which are different for small or for long times. In the first case $\mathrm{qL}$ is large, allowing both $\sinh \mathrm{qL}$ and to be approximated by $\exp \left(\frac{\mathrm{qL}}{2}\right)$. Then (13) becomes: 


$$
\mathrm{C}\left(l^{\prime}, \mathrm{p}_{0}\right)=\frac{\mathrm{k}_{\mathrm{c}} \mathrm{c}_{0}}{\mathrm{p}_{0} \mathrm{Dq}} \frac{2 \exp (-\mathrm{qL})}{\left(1-\frac{\mathrm{k}_{\mathrm{c}}}{\mathrm{Dq}}\right)\left(1+\frac{\mathrm{v}}{\mathrm{Dq}}\right)}
$$
to $^{21,47}$ :

For high enough flow rates, the equation further reduces

$$
\mathrm{C}\left(l^{\prime}, \mathrm{p}_{0}\right)=\frac{2 \mathrm{k}_{\mathrm{c}} \mathrm{c}_{0}}{\mathrm{vD}} \frac{\exp (-\mathrm{qL})}{\mathrm{q}\left(\mathrm{q}+\frac{\mathrm{k}_{\mathrm{c}}}{\mathrm{D}}\right)}
$$

Taking now the inverse Laplace transform of this equation, one finds:

$$
\mathrm{C}\left(l^{\prime}, \mathrm{t}_{0}\right)=\frac{2 \mathrm{k}_{\mathrm{c}} \mathrm{c}_{0}}{\mathrm{v}} \exp \left[\frac{\mathrm{k}_{\mathrm{c}} \mathrm{L}}{\mathrm{D}}+\frac{\mathrm{k}_{\mathrm{c}} 2 \mathrm{t}_{0}}{\mathrm{D}}\right] \operatorname{erfc}\left[\frac{\mathrm{L}}{2 \sqrt{\left(\mathrm{Dt}_{0}\right)}}+\sqrt{\left(\mathrm{t}_{0}\right)}\right]
$$

Finally, if one uses the relation $\operatorname{erfc}(x)=\frac{\exp \left(-x^{2}\right)}{\left(\tau \pi^{\frac{1}{2}}\right)}$,

which is good approximation ${ }^{48}$ for large values of $\mathrm{x}$, equation (16) becomes ${ }^{21,47}$ :

$$
\mathrm{C}\left(l^{\prime}, \mathrm{t}_{0}\right)=\frac{2 \mathrm{k}_{\mathrm{c}} \mathrm{c}_{0}}{\mathrm{v}}\left[\frac{(\mathrm{D})}{\pi}\right]^{\frac{1}{2}} \exp \left[\frac{-\mathrm{L}^{2}}{4 \mathrm{Dt}_{0}}\right]\left[\frac{\mathrm{L}}{2 \mathrm{t}_{0}^{\frac{1}{2}}}+\mathrm{k}_{\mathrm{c}} \mathrm{t}_{0}^{\frac{1}{2}}\right]
$$

Coming now to the other extreme, i.e., long time approximation $^{21,47}, \mathrm{qL}$ is small and the functions sinh $\mathrm{qL}$ and $\cosh \mathrm{qL}$ of eqn. 13 can be expanded in McLaurin series, retaining the first three terms in each of them. Then, from eqn. 13 one obtains:

$$
\mathrm{C}\left(l^{\prime}, \mathrm{p}_{0}\right)=\frac{\mathrm{k}_{\mathrm{c}} \mathrm{c}_{0}}{\mathrm{p}_{0}} \frac{1}{\left(\mathrm{Dq}+\frac{\mathrm{vk}_{\mathrm{c}}}{\mathrm{D}_{\mathrm{q}}}\right) \mathrm{qL}+\left(v+\mathrm{k}_{\mathrm{c}}\right)\left(1+\frac{\mathrm{q}^{2} \mathrm{~L}^{2}}{2}\right)}
$$

and by using equation (12) and rearranging this becomes:

$$
\mathrm{C}\left(l^{\prime}, \mathrm{p}_{0}\right)=\frac{\mathrm{k}_{\mathrm{c}} \mathrm{c}_{0}}{\mathrm{Lp}_{0}} \frac{1}{\mathrm{p}_{0}\left[1+\left(v+\mathrm{k}_{\mathrm{c}}\right) \frac{\mathrm{L}}{2 \mathrm{D}}\right]+\frac{v \mathrm{k}_{\mathrm{c}}}{\mathrm{D}}+\frac{\left(v+\mathrm{k}_{\mathrm{c}}\right)}{\mathrm{L}}}
$$

For high enough flow rates $\mathrm{k}_{\mathrm{c}}$ can be neglected compared to $v$ and $l$ can be neglected in comparison ${ }^{21,47}$ with $\frac{v \mathrm{~L}}{2 \mathrm{D}}$. For instance, in a usual experimental situation it was calculated that $\frac{v L}{2 D}=420$.Adopting these approximations, eqn. 19 reduces, after some rearrangement, to:

$$
\mathrm{C}\left(l^{\prime}, \mathrm{p}_{0}\right)=\frac{2 \mathrm{k}_{\mathrm{c}} \mathrm{Dc}_{0}}{v \mathrm{~L}^{2} \mathrm{p}_{0}} \frac{1}{\mathrm{p}_{0}+\frac{2\left(\mathrm{k}_{\mathrm{c}} \mathrm{L}+\mathrm{D}\right)}{\mathrm{D}}}
$$

Finally, inverse Laplace transformation ${ }^{49}$ of this relation yields:

$$
\mathrm{C}\left(l^{\prime}, \mathrm{t}_{0}\right)=\frac{\mathrm{kDc}_{0}}{\mathrm{v}\left(\mathrm{k}_{\mathrm{c}} \mathrm{L}+\mathrm{D}\right)}\left\{1-\exp \left[\frac{-2\left(\mathrm{k}_{\mathrm{c}} \mathrm{L}+\mathrm{D}\right) \mathrm{t}_{0}}{\mathrm{~L}^{2}}\right]\right\}
$$

By considering maximum height $\mathrm{h}$ of the sample peaks in eqn. 5 and substituting in it, the right hand side of eqn. 21 for $\mathrm{c}\left(l^{\prime}, \mathrm{t}_{0}\right)$ one obtain $\mathrm{h}$ as an explicit function of time $\mathrm{t}_{0}$. In order to linearize the resulting relation, an infinity value $\mathrm{h}_{\infty}$ for the peak height is required ${ }^{21,47}$ :

$$
\mathrm{h}_{\infty}=\frac{2 \mathrm{k}_{\mathrm{c}} \mathrm{Dc}_{0}}{\left[\mathrm{v}\left(\mathrm{k}_{\mathrm{c}} \mathrm{L}+\mathrm{D}\right)\right]}
$$

Using this expression, we obtain

$$
\ln \left(\mathrm{h}_{\infty}-\mathrm{h}\right)=\ln \mathrm{h}_{\infty}-\left[\frac{2\left(\mathrm{k}_{\mathrm{c}} \mathrm{L}+\mathrm{D}\right)}{\mathrm{L}^{2}}\right] \mathrm{t}_{0}
$$

Thus, the long enough times, for which (21) was derived, a plot of $\ln \left(\mathrm{h}_{\infty}-\mathrm{h}\right)$ versus $\mathrm{t}_{0}$ is expected to be linear ${ }^{21,47}$ and from the slope $\frac{-2\left(k_{c} L+D\right)}{L^{2}}$ a first approximate value of $k_{c}$ can be calculated from the known value of $\mathrm{L}$ and a literature or theoretically calculated value of $\mathrm{D}^{21,47}$ (Fig. 3).

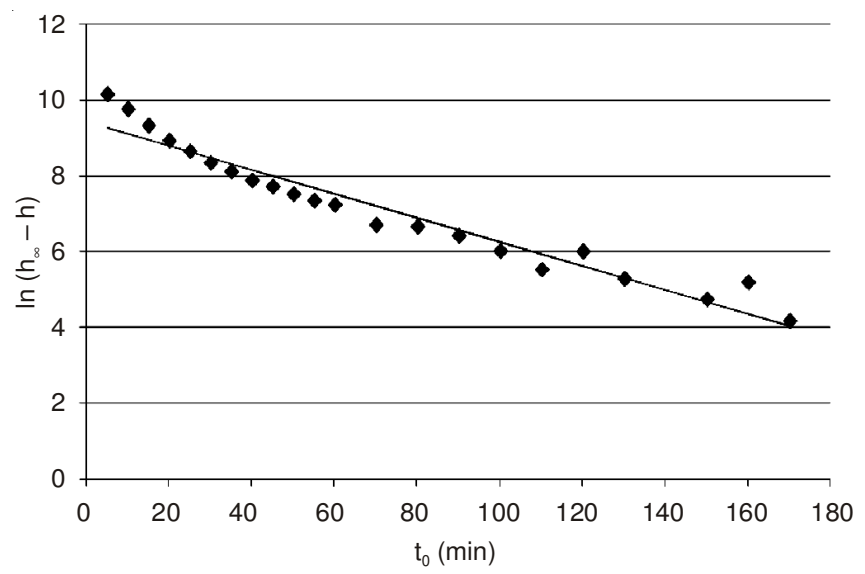

Fig. 3. Example of plotting eqn. 23 for the diffusion of liquid vapor into carrier gas at $313.15 \mathrm{~K}$ and $101.325 \mathrm{kPa} .\left(\mathrm{v}=1 \mathrm{~cm}^{3} \mathrm{sec}^{-1}\right)$

This value of $\mathrm{k}_{\mathrm{c}}$ can now be used to plot small time data according to (17) which is substituted now for $\mathrm{c}\left(l^{\prime}, \mathrm{t}_{0}\right)$ in (5). After rearrangement logarithms are taken and there results ${ }^{21,47}$ :

$$
\ln \left[\mathrm{h}\left(\frac{\mathrm{L}}{2 \mathrm{t}_{0}^{\frac{1}{2}}}+\mathrm{k}_{\mathrm{c}} \mathrm{t}_{0}^{\frac{1}{2}}\right)\right]=\ln \left[\frac{4 \mathrm{k}_{\mathrm{c}} \mathrm{c}_{0}}{\mathrm{v}\left(\frac{\mathrm{D}}{\pi}\right)^{\frac{1}{2}}}\right]-\left(\frac{\mathrm{L}^{2}}{4 \mathrm{D}}\right)\left(\frac{1}{\mathrm{t}_{0}}\right)
$$

Now, a plot of the left hand side of this relation $\frac{1}{t_{0}}$ will yield a first approximation of experimental value for $\mathrm{D}$ from the slope $\frac{-\mathrm{L}^{2}}{4 \mathrm{D}}$ of this new linear plot as shown in Fig. 4.

Preparation of the liquid for studying the effect of surfactant towards the diffusion rates and coefficient rates of the low molecular weight alcohol: The solutes used as evaporating liquids (stationary phase) were Merck alcohol and surfactant. The gases purchased from MOX (Malaysia) comprised of the carrier gas which was nitrogen of $99.99 \%$ 


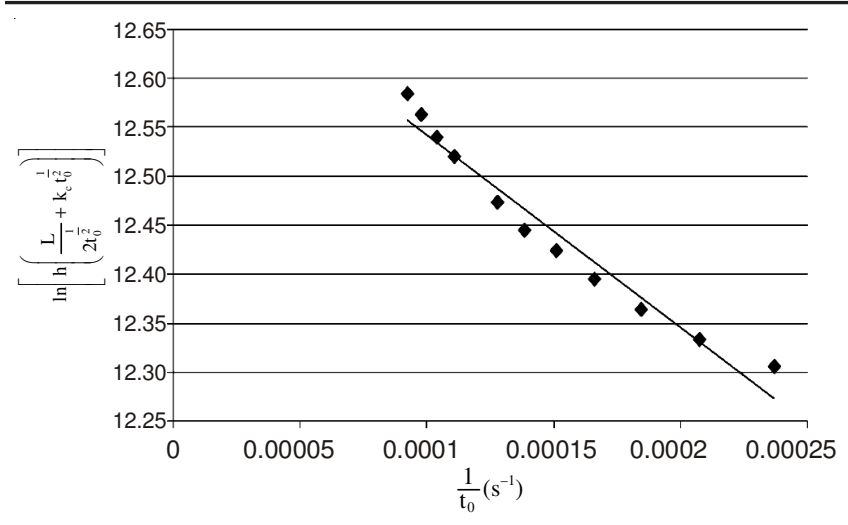

Fig. 4. Example of data from evaporation liquid vapor into carrier gas at $313.15 \mathrm{k}$ and $101.325 \mathrm{kPa}$. $\left(\mathrm{v}=1 \mathrm{~cm}^{3} \mathrm{sec}^{-1}\right)$, plotting according to eqn. 24

purity as well as the fuel gases for flame ionization detector, FID which were hydrogen of $99.99 \%$ purity and compressed air.

Preparation of surfactant-alcohol solution: The Gibbs adsorption equation for solutions of nonionic surfactants ${ }^{40}$

$$
\Gamma_{1}=-\frac{1}{1.303 \mathrm{RT}}\left(\frac{\partial \gamma}{\partial \log \mathrm{C}}\right)
$$

is used to prepare the various surfactant-alcohol solutions in order to determine the amount of surfactant per unit area. $\gamma$ is the surface tension in $\mathrm{N} \mathrm{m}^{-1}$ initially and then converted to $\mathrm{J} \mathrm{m}^{-2} \cdot \mathrm{C}_{1}$ is the molar concentration of the surfactant at the experiment absolute temperature $\mathrm{T}=298.15 \mathrm{~K}, \mathrm{R}=8.314$ $\mathrm{J} \mathrm{mol}^{-1} \mathrm{~K}^{-1}$ is ideal gas constant and $\Gamma_{1}$ is the surface excess constant of the surfactant in $\mathrm{mol} \mathrm{m} \mathrm{m}^{-2}$. The surface tension, $\gamma$ is plotted against the $\log$ of the concentration, $\mathrm{C}_{1}$ to determine the surface area per molecule, $\alpha_{1}^{s}$ as shown in Fig. 5.

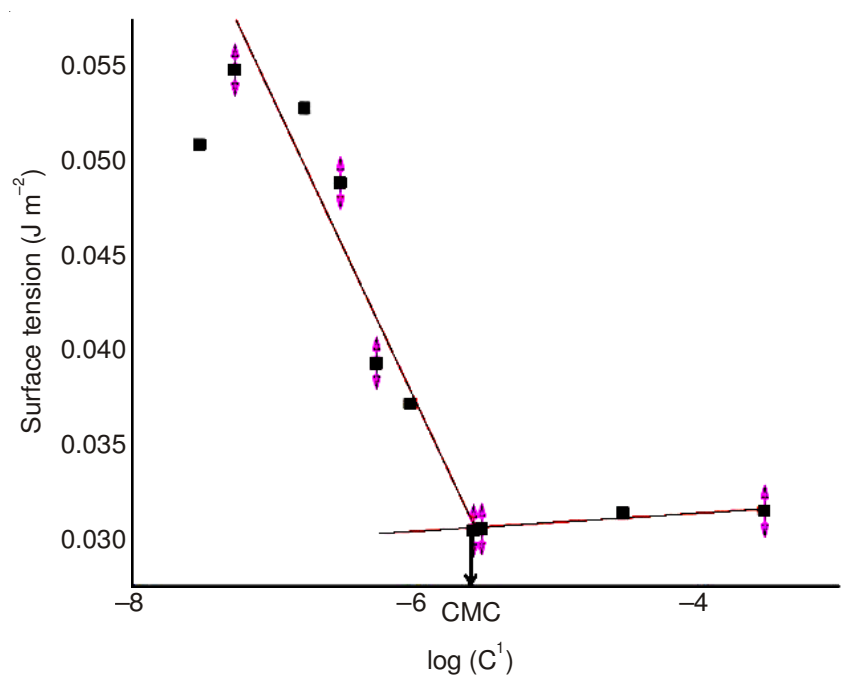

Fig. 5. Plot of the surface tension $\left(\gamma / \mathrm{J} \mathrm{m}^{-2}\right)$ against the $\log$ of $\mathrm{C}_{1}$, where is the bulk phase concentration of the various aqueous solution of surfactant, at $298.15 \mathrm{~K} . * * \mathrm{CMC}=$ Critical micelle concentration

Surface tension measurements were performed by using Tensiometer K100 by Kruss. The surface excess concentration of Tsurfactant, $\Gamma_{1}$ is calculated by using slope of the Fig. 5. From the value $\Gamma_{1}$ obtained, specific surface area per molecule at the interface is calculated as follow ${ }^{40}$ :

$$
\alpha_{1}^{\mathrm{s}}=\frac{10^{20}}{\mathrm{~N}_{\mathrm{A}} \Gamma_{1}}
$$

where $\mathrm{N}_{\mathrm{A}}$ is the Avogadro's number while $\Gamma_{1}$ is in mol m $\mathrm{m}^{-2}$. The values $\Gamma_{1}$ of and $\alpha_{1}^{\mathrm{s}}$ foundare then compared with the values of the similar homologous head group of nonionic surfactants given on the page in $^{39}$ to ensure that the values are at the same magnitude with the literature. Then, based on the theoretical coverage of surfactant monolayer, 1 monolayer is determine $^{40}$ because the correlation of the surface area of the bottle containing the evaporating liquid under study, $\mathrm{a}_{\mathrm{L}}$ as well as the specific surface area per molecule at the interface, are known. The additional monolayer is added on top of the previous added monolayer carefully by using a micrometer syringe or micropipette ${ }^{41}$ to make $2 \times$ monolayer. The procedure is repeated for the $3 \times$ monolayer and $4 \times$ monolayer.

Other experiment considering gas-liquid interface by RF-GC: The interface of the gas-liquid contributes to the gaseous pollutant(s) between the atmospheric and water environment ${ }^{23}$. Since the phenomena employs a great significance towards the environment chemistry ${ }^{42}$, the researchers must be defined about the research that they want to explore whether to study the solubilities of air pollutant in water or the ability of the liquid pollutant to migrate from water to environment. For example, dimethyl sulfide contributes as a major source of sulfur in troposphere since the pollutant is emitted by oceanic phytoplankton ${ }^{43}$. The following physiochemical quantities can be calculated when ones considered the mechanism involving in the above phenomena ${ }^{43}$ : (i) Diffusion coefficient of the pollutant in the carrier gas $\left(\mathrm{D}_{\mathrm{z}}, \mathrm{cm}^{2} / \mathrm{sec}\right)$, (ii) Diffusion coefficient of the pollutant in the water $\left(\mathrm{D}_{\mathrm{L}}, \mathrm{cm}^{2} / \mathrm{sec}\right)$, (iii) Partition coefficient of the pollutant between the water at the interface and the carrier gas (K, dimensionless), (iv) Partition coefficient of the pollutant between the bulk water and the carrier gas ( $\mathrm{K}^{\prime}$, dimensionless), (v) Partition coefficient of the pollutant between the water at the interface and the bulk ( $\mathrm{K}^{\prime \prime}$, dimensionless), (vi) Henry's law constant for the dissolution of the pollutant in the water $\left(\mathrm{H}^{+}\right.$, atm), (vii) Overall mass transfer coefficients of the gas in the carrier gas $\left(\mathrm{K}_{\mathrm{G}}, \mathrm{cm} / \mathrm{sec}\right)$ and in the liquid water $\left(\mathrm{K}_{\mathrm{L}}, \mathrm{cm} / \mathrm{sec}\right)$, (viii) $\mathrm{Gas}\left(\mathrm{k}_{\mathrm{G}}, \mathrm{cm} / \mathrm{sec}\right)$ and the liquid $\left(\mathrm{k}_{\mathrm{L}}, \mathrm{cm} / \mathrm{sec}\right)$ film transfer coefficients, (ix) Gas ( $\mathrm{r}_{\mathrm{G}}$, sec/ $\mathrm{cm})$ and liquid $\left(\mathrm{r}_{\mathrm{L}}, \mathrm{sec} / \mathrm{cm}\right)$ phase resistances for the transfer of the pollutant to the water, (x) Thickness of the stagnant film in the liquid phase $\left(\mathrm{z}_{\mathrm{L}}, \mathrm{cm}\right)$.

The setup for the experiment which is used for the abovementioned parameters is described. The only difference is an additional gas injector installed at the gas-liquid interface (Fig. 6). The procedure of the experiment is also identical from the previous.

\section{Conclusion}

The limitation of RF-GC methodologies is that the substance that being use must be volatile so that a finite fraction of its distribution in the gaseous phase can be observed. Thus for the liquid under study especially organic, volatility is rarely adequate if the molecular weight of the compound exceeds $500 \mathrm{~g} / \mathrm{mol}$. Even though by increasing the temperature up to $300{ }^{\circ} \mathrm{C}$ can improve the vitality of the liquid, but the acts may leads on decomposition of the matter. It is believed that in 


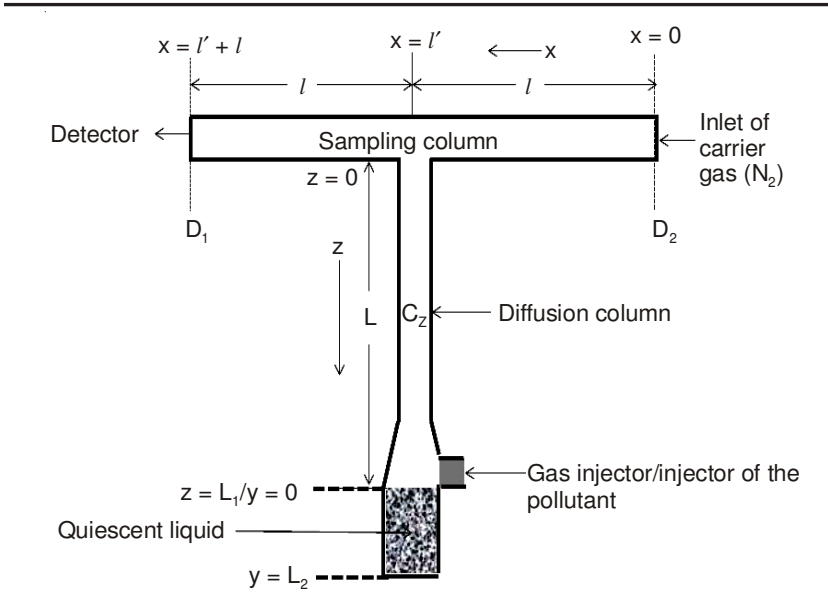

Fig. 6. Apparatus of the reversed-flow gas chromatography technique, for measuring the flux of gases across the air-water interface

case of the monolayer formation on the gas-liquid interface, there is need a further investigation on the pattern of distribution of surfactants on the surface of liquid by using BAM imager $^{44}$ in order to evaluate the distribution of monolayer on the liquid-gas interface. Furthermore, there is also needed of this method to be extended so that it can be applied to the environment analysis rather than become a dry subject by only collecting the data in the laboratory without any application to the environment. Since most of the cases the RF-GC deals with the pure liquids without any application of real world samples. The authors suggest that the set up for the RF-GC should be stretched forward so that the methodology can handle several samples at the same times. Plus, the researchers in this area should come out with solution on how to shorten the analysis time of this method since it requires at least $5 \mathrm{~h}$ and 40 min even though the sample peaks will become constant at 130-190 min after the first reversal. Since the FSG only applicable to linear molecules, the authors hope that in future this methodology could cater branched molecules, double bond and triple bond as well as aromatic compounds. Due to insufficient available experiment data, FSG could not offer the special atomic diffusion volumes for $\mathrm{F}, \mathrm{Br}$ and I thus this will open the door for the new research in this particular area ${ }^{45}$.

\section{ACKNOWLEDGEMENTS}

The authors would like to thank Malaysian Agricultural Research and Development Institute (MARDI) and Bright Sparks Unit, Skim Biasiswazah Universiti Malaya for scholarship and financial assistance. The work was also supported by a Postgraduate Research Grant (PPP) No. PG067-2013A from Institute of Research Management and Monitoring (IPPP), Universiti Malaya. The author wants to dedicate their appreciation to the staff from the Library, University of Malaya for helping to provide some of the articles.

\section{REFERENCES}

1. G. Karaiskakis and D. Gavril, J. Chromatogr. A, 1037, 147 (2004).

2. R.P. Rastogi and R.R. Misra, An Introduction to Chemical Thermodynamics, Vikas Publishing House Pvt. Ltd., New Delhi, p. 391 (1978).

3. N.A. Katsanos, G. Karaiskakis and A. Niotis, in Proceedings of the 8th International Congress on Catalysis, West Berlin: Dechema-Verlag Chemie (1984).

4. N.A. Katsanos and G. Karaiskakis, J. Chromatogr. A, 254, 15 (1983).

5. N.A. Katsanos and G. Karaiskakis, in ed.: J.C. Giddings, Advances in Chromatography, Marcel Dekker Inc.: New York. p. 138 (1984)
6. K.R. Atta, D. Gavril and G. Karaiskakis, Instrum. Sci. Technol., 30, 67 (2002).

7. N.A. Katsanos and G. Karaiskakis, J. Chromatogr. A, 237, 1 (1982).

8. G. Karaiskakis, N.A. Katsanos and A. Niotis, Chromatographia, 17, 310 (1983).

9. G. Karaiskakis, N.A. Katsanos and A. Niotis, J. Chromatogr. A, 245 , 21 (1982).

10. G. Karaiskakis, A. Niotis and N.A. Katsanos, J. Chromatogr. Sci., 22, 554 (1984).

11. G. Karaiskakis, A. Lycourghiotis and N.A. Katsanos, Chromatographia, 15, 351 (1982).

12. N.A. Katsanos, G. Karaiskakis and A. Niotis, J. Catal., 94, 376 (1985).

13. E. Dalas, N.A. Katsanos and G. Karaiskakis, J. Chem. Soc., Faraday Trans. I, 82, 2897 (1986).

14. D. Gavril, A. Koliadima and G. Karaiskakis, Chromatographia, 49, 285 (1999).

15. D. Gavril, N.A. Katsanos and G. Karaiskakis, J. Chromatogr. A, 852, 507 (1999).

16. P. Agathonos and G. Karaiskakis, J. Appl. Polym. Sci., 37, 2237 (1989).

17. K. Khalid, R.A. Khan and S.M. Zain, Am. J. Appl. Sci., 8, 428 (2011).

18. G. Karaiskakis, N.A. Katsanos, I. Georgiadou and A. Lycourghiotis, $J$. Chem. Soc., Faraday Trans. I, 78, 2017 (1982).

19. M. Kotinopoulos, G. Karaiskakis and N.A. Katsanos, J. Chem. Soc., Faraday Trans. I, 78, 3379 (1982).

20. N.A. Katsanos, G. Karaiskakis and P. Agathonos, J. Chromatogr. A, 349, 369 (1985).

21. G. Karaiskakis and N.A. Katsanos, J. Phys. Chem., 88, 3674 (1984).

22. K. Atta Rashid, D. Gavril, N.A. Katsanos and G. Karaiskakis, J. Chromatogr. A, 934, 31 (2001).

23. N.A. Katsanos and J. Kapolos, Anal. Chem., 61, 2231 (1989).

24. D. Gavril and G. Karaiskakis, Instrum. Sci. Technol., 25, 217 (1997).

25. D. Gavril, K. Atta Rashid and G. Karaiskakis, J. Chromatogr. A, 919, 349 (2001).

26. N.A. Katsanos, E. Arvanitopoulou, F. Roubani-Kalantzopoulou and A. Kalantzopoulos, J. Phys. Chem. B, 103, 1152 (1999).

27. N.A. Katsanos, E. Iliopoulou, F. Roubani-Kalantzopoulou and E. Kalogirou, J. Phys. Chem. B, 103, 10228 (1999).

28. D. Gavril and G. Karaiskakis, J. Chromatogr. A, 845, 67 (1999).

29. D. Gavril, A. Koliadima and G. Karaiskakis, Langmuir, 15, 3798 (1999).

30. D. Gavril, K.R. Atta and G. Karaiskakis, AIChE, 52, 2381 (2006).

31. K. Khalid, Oriental J. Chem., 27, 559 (2011).

32. K. Khalid, R.A. Khan and S. Mohd, Zain, A Relative New Technique to Determine Rate and Diffusion Coefficients of Pure Liquids, In Emerging Issues in the Natural and Applied Sciences, "Progress": Baku, Azerbaijan (2011).

33. K. Khalid, R.A. Khan and S.M. Zain, E-J. Chem., 8, 1916 (2011).

34. K. Khalid, R.A. Khan and S. Mohd, Studia Universitatis Babes-Bolyai Chemia, 56, 149 (2011)

35. K. Khalid, R.A. Khan and S. Mohd, Sains Malaysiana, 41, 1109 (2012).

36. K. Khalid, R.A. Khan and S. Mohd, Zain, Preliminary Studies of the Liquid Pollutants using Reversed Flow-Gas Chromatographic Methodologies, in The 5th Mathematics and Physical Sciences Graduate Congress, Chulalongkorn University (2009).

37. K. Khalid, R.A. Khan and S. Mohd, Zain, Studies of the Noxious Fluid Using RF-GC Technique, in International Synposium of Forensic Science and Environmental Health, PWTC, Kuala Lumpur (2009).

38. K. Khalid, R.A. Khan and S. Mohd, Zain, Using Reversed-Flow Gas Chromatography to Estimate Rate Coefficients and Diffusion Coefficients for Evaporation of Pure Liquid, in International Conference of Bangladesh Environment Network, Dhaka, Bangladesh (2012).

39. K. Khalid, R.A. Khan and S. Mohd, Zain, Analysis of the Liquid Pollutant using RF-GC Methodologies, in International Conference on Science and Development, Singapore (2010).

40. M.J. Rosen, Surfactants and Interfacial Phenomena, John Wiley \& Sons, New York (1989).

41. F. MacRitchie, Chemistry at Interface, Academic Press, Inc., San Diago, California (1990).

42. P.S. Liss and P.G. Slater, Nature, 247, 181 (1974).

43. J. Kapolos, Environmental Application of Reversed-Flow GC, pp. 776782 (2010).

44. Y. Moroi, M. Rusdi and I. Kubo, J. Phys. Chem. B, 108, 6351 (2004).

45. E.N. Fuller, P.D. Schettler and J.C. Giddings, Ind. Eng. Chem., 58, 18 (1966).

46. H.H. Mohammad, S.M. Zain, R.A. Khan and K. Khalid, Int. J. Environ. Sci. Dev., 4, 403 (2013)

47. N.A. Katsanos, Flow Perturbation Gas Chromatography, Marcel Dekker Inc., New York (1988).

48. M.L. Boas, Mathematical Methods in Physical Sciences, Wiley, New York (1966).

49. F. Oberhettinger and L. Badii, Tables of Laplace Transformation, Springer-Verlag (1973) 